\title{
BIOTECNOLOGIA E BIOSSEGURANÇA: ASPECTOS DE UMA ESTRATÉGIA NACIONAL DE DESENVOLVIMENTO
}

\section{BIOTECHNOLOGY AND BIOSAFETY: ASPECTS OF A NATIONAL DEVELOPMENT STRATEGY}

\author{
Agnaldo dos Santos \\ Universidade Estadual Paulista/Unesp
}

\section{RESUMO}

O texto procura indicar como a regulação da biotecnologia no Brasil está associada a uma estratégia de desenvolvimento que sugere a mudança no padrão de investimentos em ciência e tecnologia, hoje amplamente hegemonizada pela iniciativa pública. A tramitação ágil das avaliações de biossegurança, associada aos incentivos fiscais e financiamentos diretos do governo federal, buscam despertar nas empresas que atuam no território brasileiro um "espírito schumpeteriano" que as capacitem a participar ativamente do Sistema Nacional de Inovação. Mas sugerimos no texto que os processos de aquisições e fusões das empresas de sucesso nacionais pelas grandes transnacionais pode conduzir a novas formas de dependência científica-tecnológica, minando os esforços do poder público em transformar o país em um player no setor.

Palavras-chave: Inovação; biossegurança; políticas públicas de ciência e tecnologia; empresas start-ups ; concentração empresarial.

\section{ABSTRACT}

This article seeks to show how the regulation of biotechnology in Brazil is associated with a national development strategy. That suggests a change in the pattern of investment in Science and Technology, nowadays widely led by public initiative. The quickly processing of bio-safety assessments is associated with tax incentives and direct funding from the Federal Government, reach to awaken in Brazilian entrepreneurs a "Schumpeterian spirit" that enables them to actively participate in the National Innovation System. But we suggest that the processes of Mergers \& Acquisitions of successful domestic enterprises by large transnational companies can lead to a new forms of scientific-technological dependence, despite the government's efforts to transform the country in a player in the high technological industry.

Keywords: Innovation; bio-safety; public policies for science and technology; startups companies; industrial concentration 


\section{INTRODUÇÃO}

As técnicas hodiernas de manipulação de organismos vivos ou seus derivados, conhecidas genericamente de biotecnologia, apresentam um mundo de possibilidades mas também enormes dúvidas quanto à sua segurança para a saúde humana e para o meio ambiente. A despeito disso, a revolução nas pesquisas com biologia molecular desde meados dos anos 1970 atraíram vultosos investimentos por parte das science life companies, que procuram desenvolver produtos e processos devidamente protegidos por patentes, de modo a garantir o retorno de capital. É nesse contexto que os gestores públicos dos países outrora chamados de "subdesenvolvidos" procuram garantir sua participação, em um jogo extremamente competitivo e que conduz de forma inevitável a novas formas de hierarquia internacional nos planos científico e econômico.

Este texto procura apontar as estratégias que o Brasil está desenvolvendo para garantir sua participação nesse segmento. $O$ modelo de regulação das pesquisas e posterior comercialização dos organismos geneticamente modificados (OGM) está intimamente associado com as formas de incentivo à inovação tecnológica que o governo federal promove desde o final dos anos 1990, atravessando mais de quatro governos. $O$ modelo, ainda que tenha a iniciativa pública como o principal motor de desenvolvimento, procura tornar atraente o ambiente interno para os negócios das "ciências da vida" para as grandes empresas privadas estrangeiras. Tais empresas vêm absorvendo por meio de aquisições tanto as firmas tradicionais como aquelas desenvolvidas a partir das experiências de start-ups de "cientistas-empreendedores".

A Lei de Biossegurança de 2005 foi elaborada e implementada tomando essa demanda específica de parte da comunidade científica, mas, ao mesmo tempo, apresenta diferenças se comparada com suas similares norte-americana (bem mais flexível) e europeia (mais rígida). As lutas no país por uma legislação que levasse mais em consideração o "princípio da precaução" do que a "equivalência substantiva"1 explicam as idiossincrasias deste instrumento legal, que no entanto ainda é considerada por seus oponentes como excessivamente permissiva. A forma como a regulação das pesquisas e manuseio de OGM no Brasil está estruturada expressa uma resposta às demandas dos investimentos público e privado que vem ganhando corpo nos últimos anos, e pode indicar os possíveis cenários futuros.

A premissa básica apresentada no texto é a de que a inovação biotecnológica no Brasil procura utilizar o know-how desenvolvido nas instituições públicas para atrair investimentos privados nacionais e externos na área, e a legislação de biossegurança procura dar garantias legais para tais empreendimentos (bem como a legislação de propriedade intelectual, aprovada simultaneamente à primeira versão da Lei de Biossegurança nos meados da década de 1990). No entanto, tal legislação relativa à biossegurança não fica imune aos embates no meio acadêmico e na esfera política que questionam a perspectiva tecnocientífica hegemônica. Um ambiente mais seguro aos negócios estaria sendo garantido, na perspectiva do governo brasileiro, com os diversos programas e projetos de apoio à inovação desenhados na estratégia nacional de ciência e tecnologia apresentada pelo Ministério da Ciência, Tecnologia e Inovação (MCTI) para o período 2012-2015.

Dessa forma, apresentamos no item 2 a arquitetura institucional desenvolvida para

1

O princípio da precaução, adotado pelos críticos dos transgênicos, e o conceito de equivalência substantiva, adotado pelos defensores dos organismos transgênicos, são os princípios que guiam a disputa política no seio da comunidade de pesquisa. Trataremos melhor dos conceitos adiante. Cf. LACEY, 2006; LAJOLO e NUTTI, 2003. DOI da revista: http://dx.doi.org/10.12957/ric.2015.15345 
lidar com a biossegurança e os manejos biotecnológicos; no item 3 mostramos um breve perfil das empresas de biotecnologia no Brasil e a sua dinâmica de desenvolvimento; no item 4, como conclusão, descrevemos os impasses e as possíveis estratégias que o país pode adotar para ser um player na grande área de "ciências da vida".

\section{O CONSELHO NACIONAL DE BIOSSEGURANÇA E A COMISSÃO TÉCNICA NACIONAL DE BIOTECNOLOGIA}

Em 1995, o Governo Fernando Henrique Cardoso sancionou uma Lei de Biossegurança decretada pelo Congresso Nacional (Lei 8.974/95), que atribuía a um órgão técnico chamado Comissão Técnica Nacional de Biossegurança (CTNbio) a competência para liberar ou não pesquisas e comercialização com organismos geneticamente modificados. A legislação existente até então não era suficiente para dar conta das particularidades surgidas com a moderna engenharia genética, e tanto os investidores privados como parte expressiva da comunidade acadêmica ansiavam por garantias legais para seus empreendimentos. Ocorre que a estrutura legal institucional relativa à saúde humana e ao meio ambiente também era composta por dois outros órgãos federais: o Instituto Brasileiro do Meio Ambiente (IBAMA) e a Agência Nacional de Vigilância Sanitária (ANVISA). Isso levou rapidamente a um conflito de competências: a primeira avaliação e liberação de pesquisa com organismos transgênicos realizada pela CTNbio foi questionada pelo IBAMA e pela ANVISA, e uma ação de inconstitucionalidade apresentada em 1998 pelo IBAMA e pela organização não-governamental Instituto de Defesa do Consumidor (IDEC) ao Supremo Tribunal Federal levou ao questionamento da Lei de Biossegurança, que ficou em um "limbo jurídico" até a elaboração e aprovação de uma nova lei, em 2005 (Lei 11.105/05). Nesse meio tempo, safras de soja foram cultivadas com variedades transgênicas contrabandeadas da Argentina, e o Governo Lula da Silva acabou editando Medidas Provisórias que reconheciam o fato consumado e liberaram a comercialização destas safras, mesmo sem a devida avaliação, para não levar os agricultores envolvidos a enormes prejuízos.

Acompanhava o argumento jurídico da sobreposição de competências acerca da avaliação dos transgênicos outro debate, este desenvolvido na esfera científica - o quanto era seguro um organismo modificado geneticamente para ter algumas propriedades inexistentes na natureza (resistência a herbicidas e inseticidas, aumento no valor nutricional etc). Os defensores dos OGM defendem a tese da "equivalência substantiva", ou seja, a de que organismos convencionais e organismos geneticamente modificados seriam exatamente iguais em suas propriedades nutricionais, excetuando as características adquiridas em sua manipulação em laboratório (Lajolo e Nutti, 2003). De outro lado, os críticos da liberação dos transgênicos argumentam que os estudos sobre o impacto após disseminação na natureza e de seu consumo por animais e humanos ainda são insuficientes, pois o tempo para estimar isso é muito pequeno - pouco menos de três décadas, desde as primeiras plantações e comercialização de produtos com OGM (Lacey, 2006). Para esses críticos, seria preciso observar o "princípio da precaução", sugerido pela Conferência de Asilomar em 1972 e que sugere que os testes devem ser os mais exaustivos possíveis para certificar a segurança de experimentos com organismos vivos (Santos, 2003).

Foi esse o background político e científico mobilizado para tentar influenciar a elaboração da nova Lei de Biossegurança, por fim aprovada no Congresso Nacional e sancionada em 2005 no Governo Luís Inácio Lula da Silva. Em linhas gerais, a lei de 2005 indicava a CTNbio como a instituição responsável pelos estudos e aprovação técnica de estudos e segurança dos novos organismos modificados, acabando assim com a 
sobreposição de competências com o IBAMA e a ANVISA. Contudo, a liberação comercial de produtos baseados em OGM ficou a cargo do Conselho Nacional de Biossegurança (CNB), composto por ministérios cujas atribuições estejam relacionadas com o tema (Ciência e Tecnologia, Meio Ambiente, Justiça, Agricultura e Desenvolvimento), que apresentam ao presidente da República um parecer final sobre a conveniência (ou não) da liberação dos produtos e pesquisas em território nacional.

Ainda que esse formato tenha buscado contemplar parte da posição dos críticos aos transgênicos - que argumentavam que decisões político-econômicas eram travestidas de decisões técnicas na CTNbio -, estes atores sociais e políticos avaliaram que foram derrotados no embate, pois a maioria dos ministros desse conselho expressa posições que vão ao encontro dos interesses de cientistas e empresas da área da biotecnologia. A nova legislação aumentou o número de membros da CTNbio, em tese para tornar o processo decisório mais criterioso e democrático e pouco sujeito às pressões do mercado. Ocorre que sua composição (doutores com notório saber nas áreas relacionadas) tende a privilegiar os setores interessados na promoção da biotecnologia, pois formam maioria (os representantes dos direitos do consumidor, organizações nãogovernamentais e de estudos de meio ambiente acabam perfazendo a minoria dos votos). Os setores minoritários assumiram duas posições: a de "judicializar" os processos de avaliação das reuniões, com a presença de um promotor público para garantir que não fossem cometidos eventuais desrespeitos constitucionais, o que acabou irritando a maioria e aumentando as tensões no interior da comissão; a de abandonar a representação, pois acreditavam que o processo era viciado e sua presença só legitimava as decisões da maioria pró-transgênicos (Agência Carta Maior, 2006).

O fato é que desde 2005 a maioria dos pedidos de avaliação de biossegurança submetidos à comissão vem sendo aprovados, e diversos alimentos com base em organismos geneticamente modificados foram liberados para comercialização. Consultando os relatórios anuais da comissão disponíveis na internet, é possível verificar que no ano de 2005 (quando a nova lei foi promulgada) foram liberados 8 OGMs para plantio e/ou comercialização. Em 2006 estes números subiram para 125 liberações, em 2008 para 137 liberações e em 2009 tivemos 153 liberações $^{2}$. Isso tende a reforçar o coro dos críticos dos OGM, que alegam que a comissão seria muito mais um balcão a facilitar a tramitação burocrática dos interesses das science life companies do que um órgão dedicado efetivamente à verificação da biossegurança. $O$ debate sobre a liberação do feijão resistente ao mosaico dourado, doença que afeta a cultura dessa leguminosa e cujo OGM foi desenvolvido com investimento público pela Empresa Brasileira de Pesquisas Agropecuárias (EMBRAPA), indica bem os termos do conflito, que parece transcender aos argumentos científicos: defensores da tecnologia transgênica acreditam que os estudos existentes sobre os perigos destas plantas são não apenas deficientes, como caracterizam má-fé e deveriam responder em juízo (Ciência Hoje, 2013).

\section{EMPRESAS DE BIOTECNOLOGIA NO BRASIL}

O Brasil apresenta uma estrutura de Pesquisa e Desenvolvimento (P\&D) semelhante ao que existe em todo o subcontinente latino-americano: uma forte presença estatal, como algumas exceções que no entanto caminham pari passu ao setor público. Faltam na região latino-americana os investimentos privados que, somados ao aporte significativo do Estado, impulsionam a inovação e a participação da empresa privada (em áreas estratégicas como a biotecnologia) como ocorre nos EUA, na Europa ou em países

\footnotetext{
${ }^{2}$ Conforme consulta feita pelo autor em www.ctnbio.gov.br. Acessado em 19/02/2015.

DOI da revista: http://dx.doi.org/10.12957/ric.2015.15345
} 
do Sudeste asiático, como a China e a Coreia do Sul. Existem diversos fatores que concorrem para essa situação, mas os especialistas tendem a apontar questões como o problema na infraestrutura, na formação da mão-de-obra, na estrutura tributária e, principalmente, na baixa competitividade dos setores de bens de capital, que fazem a empresa nacional importar máquinas e demais insumos produtivos. Os ganhos de produtividade da indústria brasileira estão fortemente associados ao crescente deficit comercial brasileiro, que saiu de um intercâmbio superavitário de US\$ 7 bilhões em 2002 para um resultado negativo de US $\$ 50$ bilhões em 2012 (CIMM, 2013). As empresas brasileiras "inovam" importando bens de capital.

De todo modo, é possível observar desde alguns anos um esforço para reverter esse quadro, por meio de incentivos fiscais e investimentos públicos em projetos privados, sendo a chamada "Lei do Bem" (2005) um dos principais instrumentos. Com ele, busca-se incentivar a contratação de mestres e doutores em projetos de Pesquisa e Desenvolvimento das empresas, com concessão de bolsas para esses pesquisadores, incentivos fiscais para as empresas que os contratam e financiamento para aquisição de equipamentos e demais investimentos em pesquisa. Os resultados vêm se mostrando ainda muito tímidos, e o governo incentiva as empresas a utilizar esses canais públicos de apoio à inovação. Alguns autores sugerem que esse fenômeno ocorre pelas próprias características da inserção brasileira nas cadeias produtivas mundiais, em que bens de produção são oferecidos por países com maior produtividade, além dos próprios bens de consumo igualmente competitivos, desestimulando empreendimentos mais ousados; mesmo as empresas diretamente relacionadas com inovação gastam boa parte de seus recursos com aquisição de tecnologia importada e sem nenhum interesse de transferência de know-how (DAGNINO, 2007).

Um olhar para a área de biotecnologia pode ajudar a compreender melhor esse fenômeno. Consideremos a pesquisa $A$ Indústria de Biociências Nacional - caminhos para o crescimento (2011) organizada por BioMinas, instituição patrocinada pelas empresas de biotecnologia e biociências do estado de Minas Gerais. Vemos ali que 103 empresas deste segmento que responderam seu questionário (de um total de 143) utilizam majoritariamente recursos públicos para promover inovação (69\%). Aquelas que, além destes recursos públicos, utilizam de forma complementar seus próprios recursos totalizam $58 \%$.

Um primeiro olhar poderia sugerir que os esforços do governo federal em incentivar a inovação apresentariam resultados razoáveis nessa área, uma vez que quase $60 \%$ do universo aqui considerado aporta recursos próprios em P\&D. Ocorre que, na comparação com as economias nacionais com a primazia em desenvolvimento tecnocientífico, as proporções são exatamente inversas, como sugerido acima. Enquanto nos EUA os segmentos econômicos baseados em alta tecnologia chegam a $20 \%$ do total das empresas, no Brasil o percentual mal chega a 1\%, e mesmo assim tais empresas lançam produtos no mercado já existentes (DAGNINO, 2007, p. 48). Se ampliamos o escopo das empresas aqui analisadas, verificaremos que 29 mil empresas teriam potencial exportador mas apenas 3 mil delas demandaram os recursos oferecidos pelo governo federal (IPEA, 2010, p. 55).

De uma maneira geral, a empresa de biotecnologia no Brasil é relativamente nova, sendo a Embrapa uma das pioneiras, criada no contexto desenvolvimentista da ditadura militar, nos anos 1970. As empresas que existiam no país desenvolviam técnicas melhoristas nas plantas e animais, mas as técnicas de transgenia só passaram a fazer parte do seu cotidiano nas últimas três décadas. $E$ empresas foram incubadas em experimentos desenvolvidos pelas universidades, principalmente na região Sudeste do país. É neste contexto que emerge a figura do "cientista-empreendedor", normalmente pesquisador do setor público que resolve utilizar sua expertise para iniciar uma start-up 
capaz de gerar produtos e processos com mais agilidade do que na burocracia estatal.

Dois exemplos sempre lembrados no país são a Allelyx, empresa que se especializou no sequenciamento do DNA de fitopatógenos (organismos que atacam plantas), e a Canaviallis, empresa focada no melhoramento da cana-de-açúcar por meio de técnicas transgênicas (SANTOS, 2011). Ambas foram engendradas no contexto universitário, em geral por professores que abandonaram a dedicação exclusiva no setor público e passaram a atuar part-time, ou então se desligaram totalmente do emprego público mas continuaram inseridos em networks formadas pelos pesquisadores das universidades, em clusters e condomínios empresariais formados próximos aos centros de pesquisas (como é o caso das duas empresas citadas, instaladas próximas à Universidade de Campinas, no estado de São Paulo). Estes dois exemplos são significativos também devido ao destino que tiveram: receberam incentivos públicos do governo do estado de São Paulo e do governo federal, captaram recursos em um fundo de investimentos brasileiro (Votorantin Novos Negócios), e depois de aumentarem seu valor de mercado, foram vendidas para a empresa multinacional Monsanto, em um típico processo de concentração de capitais. É muito reveladora a reação de um dos cientistasempreendedores envolvidos, Fernando Reinach, ante as críticas de autoridades do governo à época da negociação da Allelyx: a venda da empresa representava o sucesso do empreendimento, não o seu fracasso (OESP, 2008).

Como temos argumentado no texto, toda a estrutura de regulamentação e de apoio à inovação em biotecnologia no Brasil tende a levar a este tipo de solução empresarial. 0 processo de oligopolização no segmento das "ciências da vida" não é novidade e foi acelerado nos últimos anos. Apenas a título de exemplo, no ano 2000 somente três empresas controlavam $20 \%$ do mercado mundial (em 1994 doze empresas representavam esse mesmo percentual), sendo que as dez principais empresas eram responsáveis por $31 \%$ das vendas de produtos relacionados às técnicas de biotecnologia (GUERRANTE, 2003, p. 103).

Ocorre que o perfil das empresas brasileiras envolvidas com inovação descrito acima atribui características mais daninhas a este processo. É preciso verificar se as metas estabelecidas na estratégia nacional de desenvolvimento científico-tecnológico podem acelerar ou mudar a rota da "fagocitização" do potencial biotecnológico brasileiro.

\section{UMA ESTRATÉGIA NACIONAL DE DESENVOLVIMENTO}

No documento Estratégia Nacional de Ciência, Tecnologia e Inovação: 2012-2015 (MCTI, 2012, p. 34), o governo federal aponta que a vocação do Brasil é a de desenvolver uma "economia de conhecimento da natureza", pois a riqueza da biomassa nacional indicaria a necessidade de explorar as potencialidades da agricultura, pecuária, mineração e indústria farmacêutica com maior valor agregado a partir da inovação de produtos e processos. Neste sentido, indica a necessidade de superar a modesta capacidade de inovação e sua participação no mercado externo, ainda muito dependente de commodities de baixo valor agregado, que segundo o próprio documento (usando dados do Instituto de Pesquisas Econômicas Avançadas - IPEA) aumentou seu percentual na pauta de exportações após a crise de 2008 para 51\%, com deficit na balança comercial no segmento de produtos de alta/média tecnologia de U\$10,1 bilhões em 2007 para US $\$ 28,4$ bilhões em 2010, aumento de $184 \%$ (p. 37).

Uma estratégia a ser construída deve levar em conta, de acordo com o documento, os recursos da biotecnologia e nanotecnologia, bem como o desenvolvimento de fontes energéticas de baixo carbono. Para o governo, é preciso avançar mais no estímulo aos investimentos privados em inovação, que atingiriam o percentual de $45,7 \%$ do total de 
gastos nesse segmento, razoável diferença quando consideramos os gastos privados de $67,3 \%$ com P\&D e inovação nos EUA, 71,7\% na China e 72,9\% na Coreia do Sul (p. 41). Pelos cálculos do Ministério da Ciência, Tecnologia e Inovação, será preciso que as empresas privadas invistam em $P \& D$ algo como $R \$ 24$ bilhões para que se dobre 0 investimento que era feito em 2008 , elevando o percentual para $0,9 \%$ em relação ao PIB (p. 44). Isso poderá ocorrer: 1) fortalecendo o sistema de financiamento em P\&D, 2) transformando efetivamente a Financiadora de Estudos e Pesquisas (FINEP) em um real "banco de inovação", 3) promovendo a revisão da legislação acerca dos investimentos externos diretos para vinculá-los à internalização de centros de pesquisa no país, 4) promover a ampliação dos projetos "Pesquisador nas Empresas", 5) estímulo e desburocratização dos mecanismos de direitos de propriedade intelectual, 6) ampliação do programa "Ciência Sem Fronteiras", entre outras medidas (pp. 44-52).

De uma forma geral, o documento vai listando toda a revisão no marco legal e as reorientações para setores considerados estratégicos, mas deixa claro uma aposta na capacidade das empresas brasileiras ou instaladas no seu território de se envolver na construção de um efetivo Sistema Nacional de Inovação. Mas já tivemos a oportunidade de indicar que a forma de inserção do Brasil nas cadeias produtivas globais tende a desestimular o capital privado a investir em processos de P\&D. Também conspira contra essa restruturação e reinserção industrial/científica/tecnológica a apreciação cambial que se seguiu à crise de 2008, que tende a tornar as exportações brasileiras menos competitivas. O Brasil recebeu US\$ 66 bilhões em 2011 e, em 2012, US\$ 65,3 bilhões de investimento estrangeiro direto. Mesmo com a pequena queda, indica um forte interesse das empresas multinacionais neste mercado. Boa parte das empresas estrangeiras optam pela aquisição das que já existem no país, movimentou que continuou mesmo após a crise internacional de 2008 (BBC Brasil, 2013), acentuando a oligopolização do setor. Isso nos leva novamente para a questão da regulação da biossegurança.

Boa parte dos pedidos de análise na CTNbio são de experimentos com OGM desenvolvidos pelas grandes science life companies, de capital estrangeiro: Monsanto, Bayer, Syngenta etc (CTNbio, 2013). Um bom exemplo é o pedido para a liberação da soja transgênica da Monsanto. Após sua liberação pela comissão, a Monsanto estabeleceu um contrato de licenciamento desta variedade com a Embrapa, que pesquisa formas de adaptar a semente transgênica aos solos brasileiros. Mesmo que não esteja nos atuais planos do governo federal qualquer tipo de privatização da empresa (Valor Econômico, 2013), a aproximação destas duas indica o tipo de atuação que a transnacional pretende desenvolver no país, além da aquisição de start-ups bemsucedidas. O próprio comportamento dos membros da CTNbio - geralmente muito solícitos aos pedidos de aprovação, logo defendidos por pesquisadores que lançam mão de argumentos que desqualificam seus opositores (Ciência Hoje, 2013) - nos leva a concluir que a comissão é hoje importante elemento institucional para a promoção da biotecnologia no Brasil, em especial aquela desenvolvida pelos grandes players mundiais. Em que pese os esforços do governo federal e de diversos governos estaduais no sentido de desenvolver uma cultura de inovação no setor privado e de constituir um Sistema Nacional de Inovação, a dinâmica dos atores neste segmento é a de acomodação a uma estrutura internacional existente, e os apelos dos gestores públicos aos "instintos schumpeterianos" do empresariado até agora encontraram poucos ouvidos.

Os estudos sobre inovação e estratégias nacionais de desenvolvimento tendem a mostrar que não existem modelos que possam ser plenamente copiados por países com histórias singulares e com suas particularidades, distintas portanto dos países que iniciaram antes seu desenvolvimento científico e tecnológico (CHANG 2004; FREEMAN e SOETE, 2008; ROSENBERG, 2006). Contudo, é possível identificar nos países que lograram algum êxito certos aspectos cruciais: forte planejamento estatal, amparado por

DOI da revista: http://dx.doi.org/10.12957/ric.2015.15345 
uma burocracia recrutada nas melhores escolas, com intensa interlocução com um setor privado orientado para o crescimento no mercado exterior; mecanismos de transferência de tecnologia, em especial por meio de joint-ventures; maciços investimentos em recursos humanos, desde a escola básica até a universidade; estruturação de uma infraestrutura condizente com taxas crescentes de crescimento (EVANS, 2004; CHANG, 2004; NELSON, 2006).

Os gestores públicos responsáveis no Brasil pela política de ciência e tecnologia demonstram por meio dos documentos oficiais que conhecem estas reflexões, contudo o resultado geral reforça a tese de que os caminhos convencionais de mercado não levarão a profundas alterações na estrutura industrial e nos mecanismos de P\&D. Configura-se como uma hipótese bem plausível que o modelo adotado para desenvolver a biotecnologia brasileira, inspirada na aposta de empreendedores capitalistas fortalecendo um Sistema Nacional de Inovação, reforçará a dependência tecnológica em relação às matrizes das transnacionais, que já dominam os mercados de sementes e farmacêutico. O patenteamento de técnicas e produtos desenvolvidos por laboratórios públicos e privados brasileiros acabam se transformando em ativos significativos quando da decisão das transnacionais em comprar empresas aqui desenvolvidas. Será necessário acompanhar os passos que seguirão o governo reeleito em 2014 no sentido de desarmar algumas armadilhas econômicas (como a apreciação da moeda e a forte dependência das commodities) no caminho de um desenvolvimento mais sustentável e duradouro.

De todo modo, é preciso avaliar quais tipos de tecnologia o país deve escolher para romper com a condição subalterna em que ainda se encontra. É possível que a expertise adquirida nas "ciências da vida" e nas indústrias de softwares, por exemplo, sejam orientadas para estratégias de tecnologia social, onde os ditames mercantis sejam relativizados em prol de um desenvolvimento desde as necessidades locais e regionais (DAGNINO, 2004). Sugerimos em outro texto que a similaridade entre a biotecnologia e a informática, mesmo considerando que o determinismo no primeiro caso é muito mais passível de críticas, abre espaço para estratégias open source, condizentes com o conceito de tecnologia social $(X, 2011)$. Ainda que esteja no plano genérico das propostas (experiências como o projeto Genoma Fapesp são, no entanto, bons modelos de trabalho colaborativo), tais caminhos se apresentam como mais promissores para um efetivo desenvolvimento nacional.

\section{REFERÊNCIAS BIBLIOGRÁFICAS}

AGÊNCIA Carta Maior. Divergência política paralisa a nova CTNbio. Disponível em <http://www.cartamaior.com.br/templates/materialmprimir.cfm?materia id=11417>.

Acessado em 07/04/2013.

BBC Brasil. Investimento estrangeiro no Brasil cai mas segue 'robusto', diz UNCTAD. Disponível

em:

$<$ http://www.bbc.co.uk/portuguese/noticias/2013/01/130123 unctad df.shtml>. Acessado em 07/04/2013.

BIOMINAS Brasil e PwC Brasil. A Indústria de Biociências Nacional - caminhos para o crescimento. Belo Horizonte, 2011.

CHANG, Ha-Joon. Chutando a Escada: a estratégia do desenvolvimento em perspectiva histórica. São Paulo, Editora da Unesp, 2004.

CENTRO de Informação Metal Mecânico (CIMM). Ganho de produtividade è movido por importação de equipamentos. Disponível em <http://www.cimm.com.br/portal/noticia/exibir noticia/10258-ganho-de-produtividade-emovido-por-importacao-de-equipamentos> . Acessado em 21/04/2013. 
CIÊNCIA Hoje. Polêmica à Mesa. Disponível em $<$ http://cienciahoje.uol.com.br/noticias/2013/04/polemica-a-mesa >. Acessado em 20/04/2013.

COMISSÃO Técnica Nacional de Biotecnologia (CTNBio), Brasil. Tabela Geral de Plantas Geneticamente Modificadas Aprovadas Comercialmente. Disponível em $<$ http://www.ctnbio.gov.br/index.php/content/view/17811.html >. Acessado em 21/04/2013. DAGNINO, Renato. "A tecnologia social e seus desafios". In: Tecnologia social: uma estratégia para o desenvolvimento. Rio de Janeiro, Fundação Banco do Brasil, 2004.

---.--. Ciência e Tecnologia no Brasil: o processo decisório e a comunidade de pesquisa. Campinas: SP, Editora da Unicamp, 2007.

O ESTADO de São Paulo (OESP). Ministro critica venda da Alellyx e da Canavialis para a Monsanto. Disponível em <http://www.estadao.com.br/noticias/impresso,ministro-criticavenda-de-alellyx-e-canavialis-para-a-monsanto,272555,0.htm>. Acessado em 07/04/2013. EVANS, Peter B. Autonomia e Parceria: Estados e transformação industrial. Rio de Janeiro, Editora UFRJ, 2004.

FREEMAN, Chris; SOETE, Luc. A Economia da Inovação Industrial. Campinas: SP, Editora da Unicamp, 2008.

GUERRANTE, Rafaela Di Sabato. Transgênicos - uma visão estratégica. Rio de Janeiro, Interciência, 2003.

IPEA. Brasil em Desenvolvimento - planejamento e políticas públicas: sumário analítico. Instituto de Pesquisa Econômica Aplicada. Brasília, 2010.

LACEY, Hugh. A Controvérsia sobre os Transgênicos - questões científicas e éticas. Aparecida: São Paulo, Ideias e Letras, 2006.

LAJOLO, Franco Maria; NUTTI, Marília Regini. Transgênicos - Bases científicas de sua segurança. São Paulo, SBAN, 2003.

MINISTÉRIO da Ciência, Tecnologia e Inovação (MCTI), Brasil. Estratégia Nacional de Ciência, Tecnologia e Inovação: 2012-2015. Brasília: DF, MCTI, 2012.

NELSON, Richard R. As Fontes do Crescimento Econômico. Campinas: SP, Editora da Unicamp, 2006.

PRESIDÊNCIA da República, Brasil. Lei 11.105 de 2005. Disponível em $<$ http://www.planalto.gov.br/ccivil 03/ ato2004-2006/2005/lei/l11105.htm>. Acessado em 07/04/2013.

ROSENBERG, Nathan. Por Dentro da Caixa Preta - Tecnologia e Economia. Campinas: SP, Editora da Unicamp, 2006.

$\mathrm{X}, 2011$.

SANTOS, Laymert Garcia dos. Politizar as Novas Tecnologias - o impacto sócio-técnico da informatização digital e genética. São Paulo, Editora 34, 2003.

VALOR Econômico. Os novos desafios que norteiam a Embrapa. Disponível em: <http://www.valor.com.br/agro/3094926/os-novos-desafios-que-norteiam-embrapa>.

Acessado em 22/04/2013.

Recebido: 26/02/2015

Aprovado: 28/06/2015 